\title{
Ensaio do Túnel 2 do Sistema Cantareira de
} Adução de Água para a Região Metropolitana de São Paulo - Resgate Histórico e Tecnológico

Hemerson D. Pinheiro*

Marcius F. Giorgetti**

\section{ReSUMO}

Este artigo resgata um trabalho realizado entre o final da década de 1960 e início da década de 1970, pela Cátedra de Mecânica dos Fluidos (precursora do Departamento de Hidráulica e Saneamento da Escola de Engenharia de São Carlos - Universidade de São Paulo), que teve como objetivo prever a vazão de água do Túnel 2 do Sistema Cantareira de Abastecimento de Água para a Região Metropolitana de São Paulo. Nesta galeria foi realizado um ensaio original com circulação de ar, para o qual foram desenvolvidos métodos e técnicas a fim de verificar a vazão e auxiliar no seu dimensionamento, para garantir uma adução de 33 $\mathrm{m}^{3} / \mathrm{s}$. Mediante o levantamento, organização cronológica e análise dos documentos produzidos pelos autores do referido ensaio, resgatam-se as influências teóricas que nortearam as metodologias, as técnicas e tecnologias, e analisam-se, de acordo com os registros documentais, a execução e resultados alcançados pelos ensaios.

Palavras-chave: Ensaio de túnel de adução; Sistema Cantareira; Relato histórico.

\section{INTRODUÇÃO}

Com a finalidade de suprir as demandas por água potável para a Região Metropolitana de São Paulo (RMSP), a Companhia Metropolitana de Água de São Paulo (Comasp) iniciou no ano de 1967 a construção do Sistema Cantareira. Este é

\footnotetext{
*Possui graduação em Matemática pela Universidade Estadual de Maringá (1999), graduação em Engenharia Civil pelas Faculdades Integradas de São Carlos (2007) e mestrado em Engenharia Hidráulica e Saneamento pela Universidade de São Paulo (2007). Atualmente é aluno de doutorado da Universidade de São Paulo: hemerson@usp.br.

**Possui graduação em Engenharia Mecânica pela Universidade de São Paulo (1960), mestrado em Mechanical Engineering - Ohio State University (1968), doutorado em Engenharia Hidráulica e Saneamento pela Universidade de São Paulo (1971) e pós-doutorado em Environmental Engineering Sciences pela University of Florida (1976/77). Atualmente é professor-titular da Universidade de São Paulo - USPEESC e professor-titular em tempo parcial na Escola de Engenharia de Piracicaba: marciusg@sc.usp.br.
} 
o maior sistema adutor de água para a região metropolitana de São Paulo. Capta água dos rios Jaguari, Jacareí, Cachoeira, Atibainha e Juqueri. Aduz 33 mil litros de água por segundo, abastecendo 8,8 milhões de pessoas nas zonas norte, central, parte da leste e oeste da capital e os municípios de Franco da Rocha, Francisco Morato, Caieiras, Guarulhos (parte), Osasco, Carapicuíba, Barueri (parte), Taboão da Serra (parte), Santo André (parte) e São Caetano do Sul (Sabesp, 2006).

A construção desse sistema representou um grande salto, tanto na quantidade quanto na qualidade da água tratada oferecida à RMSP. Trouxe também importantes inovações às técnicas de tratamento de água do Brasil e América Latina (Azevedo Netto et al., 1978).

O Túnel 2, com extensão de 4.826 m, é o último túnel entre os sete que compõem o sistema (figura 1); faz a ligação entre o reservatório de Águas Claras e a ETA Guaraú, aduzindo $33 \mathrm{~m}^{3}$ de água por segundo. Esta não foi a vazão projetada para o túnel. O projeto inicial do Sistema Cantareira previa uma vazão máxima de $22 \mathrm{~m}^{3} /$ s para o Túnel 2 e para essa vazão ele foi escavado. Estudos posteriores à escavação do túnel concluíram que a capacidade do Sistema Cantareira poderia ser ampliada para $33 \mathrm{~m}^{3} / \mathrm{s}$; comisso, se tornou necessária a modificação das dimensões do túnel. Frente a essa necessidade, a Escola de Engenharia de São Carlos (EESC) da Universidade de São Paulo (USP), mais precisamente o Departamento de Hidráulica e Saneamento (SHS), foi então contratado para realizar uma assessoria quanto ao redimensionamento do Túnel 2, por meio do estudo das perdas de carga.

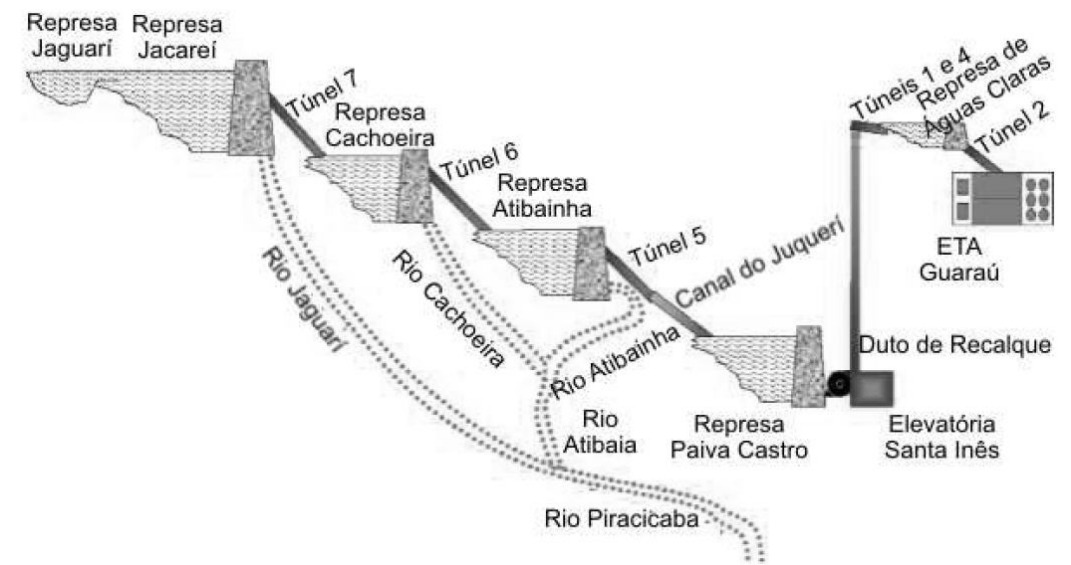

Figura 1. Perfil Hidráulico esquemático do Sistema Cantareira (sem escala). Fonte: Sabesp, 2006.

O estudo das perdas de carga no Túnel 2 constou de dois ensaios com circulação de ar, realizados no próprio túnel e em modelos reduzidos. Neles foram avaliadas as 
perdas quando da circulação de água a partir dos dados obtidos para a vazão forçada de ar. O objetivo do primeiro ensaio, realizado durante as obras de rebaixamento, foi auxiliar no redimensionamento, e o segundo teve como finalidade verificar se, ao final das obras, o túnel atenderia à vazão de projeto $\left(33 \mathrm{~m}^{3} / \mathrm{s}\right)$.

Com os resultados dos ensaios de campo e de laboratório, foi obtida a curva característica de perda de carga do Túnel 2 no escoamento de água a partir do escoamento de ar.

É sobre as técnicas e tecnologias empregadas nesses dois ensaios que versa esta pesquisa, com o objetivo de dar início à construção de uma historiografia da tecnologia produzida pelo Departamento de Hidráulica e Saneamento (SHS) da Escola de Engenharia de São Carlos (EESC). Para tanto, foram abordados os trabalhos realizados entre o final da década de 1960 e início da década de 1970 pela Cátedra de Mecânica dos Fluidos, precursora do SHS, na determinação das perdas de carga do Túnel 2 do Sistema Cantareira.

\section{Os ensaios do Túnel 2}

Os ensaios de perda de carga no Túnel 2 do Sistema Cantareira constaram da medida da diferença de pressões totais que se estabeleceram entre o emboque e o desemboque da galeria para um escoamento de ar. A partir dos dados obtidos nos ensaios, foram estimadas as perdas de carga quando se escoasse água.

O primeiro ensaio, realizado em julho de 1969, teve como objetivo, a partir dos dados das perdas de carga com a circulação de ar, fazer a previsão da vazão de água que passaria pelo túnel nas condições de desnível estabelecidas no projeto entre montante e jusante, no estado em que se encontrassem as obras de rebaixamento sugeridas para o aumento da vazão de $22 \mathrm{~m}^{3} / \mathrm{s}$ para $33 \mathrm{~m}^{3} / \mathrm{s}$. O segundo ensaio foi realizado em 1972, no final das obras de adaptação impostas pelo ensaio preliminar, com o objetivo de verificar, definitivamente, a capacidade de adução do Túnel 2.

As determinações da perda de carga global foram realizadas para diversas vazões do escoamento de ar, dentro das possibilidades de operação dos ventiladores existentes. Os resultados foram colocados em forma de curva característica de perda de carga do túnel, mantida a geometria existente.

A medida de perda de carga foi feita com tubos de Pitot, colocados adequadamente no emboque e no desemboque. $\mathrm{O}$ escoamento foi considerado como unidimensional, em face da preponderância das dimensões longitudinais da galeria, com relação às suas dimensões transversais, de maneira a se obter a maior precisão possível nas medidas.

A vazão de ar foi aferida com medidor de orifício do tipo diafragma, inserido em trecho retilíneo do emboque, no ensaio preliminar, e no desemboque do túnel, em 
trecho revestido, no segundo ensaio. O diafragma foi projetado e construído tomandose as precauções estabelecidas em normas e de maneira a ser facilmente montado e transportado; calibrado por meio de um modelo reduzido; e o seu coeficiente de vazão, em função do número de Reynolds, obtido dentro da gama de variação correspondente ao escoamento no túnel. O escoamento forçado de ar através da galeria foi feito com três ventiladores SEI adquiridos pela COMASP, montados no desemboque.

Em túneis hidráulicos, o conhecimento do perfil escavado é fundamental no cálculo das perdas e no projeto dos revestimentos. As medidas dos perfis da seção de um túnel podem ser usadas também para a verificação da quantidade de sobreescavação e subescavação, isto é, os desvios da seção transversal de um túnel em relação ao projeto de escavação durante a execução; é importante também para o acompanhamento dos deslocamentos, achatamentos e mudanças na seção do túnel com o passar dos anos.

Frente à necessidade da realização do levantamento das seções do Túnel 2, a equipe responsável pela previsão da perda de carga desenvolveu um equipamento e um método específicos para determinar suas áreas e seus perímetros, que foi denominado Método Óptico.

O levantamento foi solicitado pela Comasp, com a finalidade de ser o "as built" para as seções da galeria que estava sendo finalizada para uma vazão de projeto 22 $\mathrm{m}^{3} / \mathrm{s}$; o levantamento foi utilizado também para o estudo da disposição dos equipamentos necessários para a execução dos ensaios com circulação de ar e construção dos modelos reduzidos dos trechos do túnel onde foram instalados os diafragmas.

Segundo Remenieras e Bourguignon (1953a), a estimativa da perda de carga no escoamento de água, a partir da perda obtida quando do escoamento de ar, baseiase no fato de que o fator de perda de carga $(\lambda)$, da fórmula universal da perda de carga por unidade de comprimento (Equação 1), para um mesmo número de Reynolds do escoamento em uma canalização de um fluido incompressível em regime permanente, independe da natureza do fluido que escoa, água ou ar no escoamento incompressível. Nas condições em que os ensaios foram realizados, o escoamento de ar é considerado incompressível devido às baixas velocidades, inferiores a um quarto da velocidade do som.

$$
J=\frac{\lambda}{D} \frac{V^{2}}{2 g}
$$

Na equação, 1 J é a perda de carga por unidade de comprimento; D, o diâmetro 
hidráulico da canalização; V, a velocidade média do fluido; g, a aceleração da gravidade; $\lambda$, o coeficiente de perda de carga que é uma função do número de Reynolds do escoamento $($ Rey $=\mathrm{VD} / \mathrm{v})$ e da rugosidade relativa da parede $\varepsilon / \mathrm{D}$ ( $v$ é a viscosidade cinemática do fluido).

Para fornecer a vazão de ar no túnel, foram utilizados três grandes ventiladores. Tanto no ensaio preliminar quanto no segundo, os ventiladores foram fixados no desemboque do túnel e funcionaram como exaustores (Figuras 2 e 3). A escolha da seção para instalação foi auxiliada pelo método óptico desenvolvido por docentes do SHS.

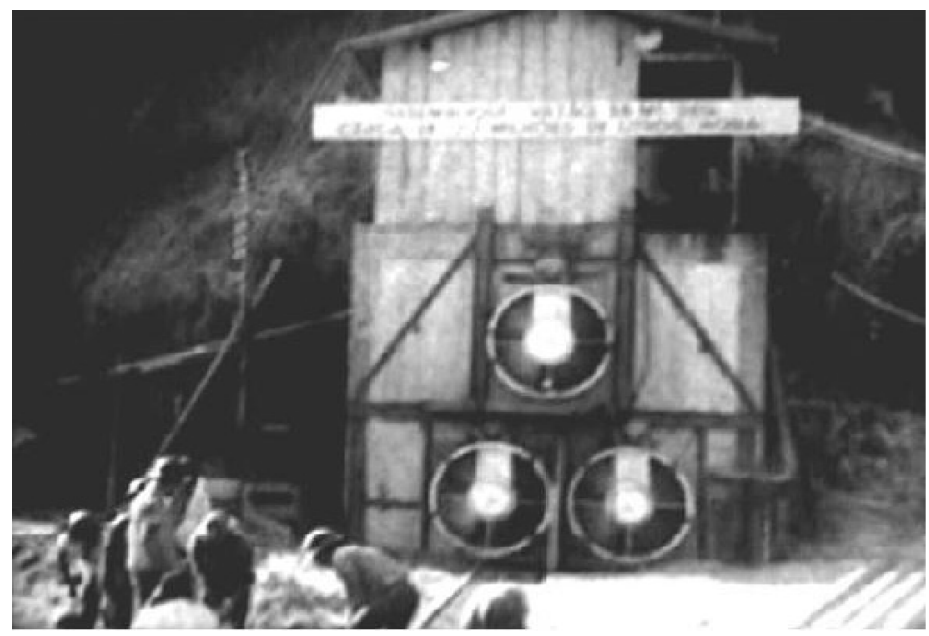

Figura 2. Instalação dos ventiladores no ensaio preliminar.

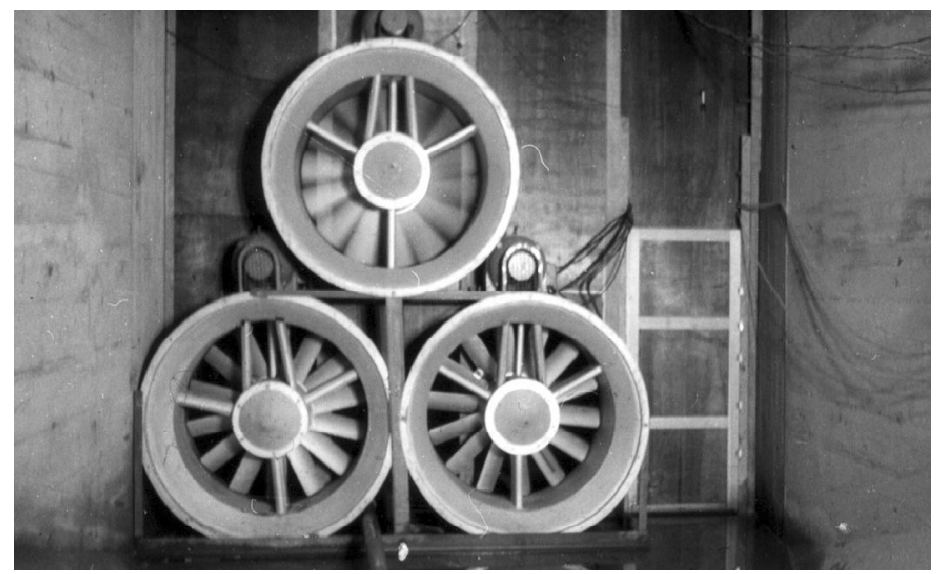

Figura 3. Instalação dos ventiladores no segundo ensaio. 
No ensaio preliminar (Figura 2), os ventiladores foram instalados na cota zero, pois era o único trecho de desemboque que estava revestido, o que facilitou a montagem dos equipamentos. No segundo ensaio (Figura 3), eles foram instalados na progressiva $8 \mathrm{~m}$, com referência ao desemboque. Nessa progressiva a seção é retangular, com dimensões de 4,20 m de largura e $3,78 \mathrm{~m}$ de altura, o que possibilitou a execução de uma passagem e permitiu livre acesso ao interior do túnel.

No túnel, com o uso combinado dos ventiladores, foram obtidas as diferentes vazões necessárias para o levantamento dos pontos da curva de perda de carga. Duas flanges cegas de madeira foram executadas e ajustadas aos ventiladores 1 e 2 e uma terceira tampa de área variável ao ventilador 3 , de modo a obter, por exemplo, a vazão de 1 e 1/2 ventiladores. Dessa forma, foi possível obter vazões abaixo da vazão máxima obtida com os três ventiladores trabalhando em plena abertura.

A medida precisa da vazão de ar foi indispensável para o estabelecimento das condições de semelhança necessária à previsão da perda de carga no escoamento de água.

Para os ensaios realizados no Túnel 2, foi considerada como solução mais viável a medida da vazão com orifício calibrado, no caso um diafragma, devido às grandes facilidades de construção e de medida que ele proporciona. Outra vantagem inerente ao medidor do tipo de orifício é que a vazão pode ser imediatamente estimada, permitindo que a qualidade do ensaio fosse constantemente avaliada (SHS, 1972). Quanto à precisão, para qualquer diafragma, independente da geometria da seção onde é instalado, pode-se sempre obter sua curva de calibração fazendo-se uso de modelos reduzidos ensaiados em laboratório, atingindo-se, dessa forma, resultados bastante satisfatórios.

Tanto para o ensaio preliminar quanto para o segundo ensaio foi calibrado em laboratório o modelo reduzido dos diafragmas utilizados.

As velocidades foram medidas com uma bateria de tubos de Prandtl ligados a um manômetro múltiplo, especialmente construído para o ensaio. As medidas de perda de carga foram efetuadas de maneira parcialmente controlada, para permitir a possibilidade de recobrimento dos vários valores obtidos e possibilitar a determinação das características dos vários trechos de interesse.

Considerando-se os diversos trechos em que o túnel foi dividido, as condições para a semelhança entre o escoamento de ar e de água foram aplicados a cada trecho; assim, por meio das curvas de perda de carga em função da vazão, obtidas no ensaio para cada trecho, se obteve o valor correspondente da perda de carga no escoamento de água quando a vazão através do túnel fosse de $33 \mathrm{~m} 3 / \mathrm{s}$.

A partir dos resultados do ensaio preliminar, foi concluído que a perda total, quando a vazão de água no Túnel 2 fosse de $33 \mathrm{~m}^{3} / \mathrm{s}$, seria de $20,15 \mathrm{~m}$ de coluna 
d'água. Como a perda total na realidade deveria ser igual à diferença de nível existente entre as cotas $857,10 \mathrm{~m} \mathrm{e} 847,40 \mathrm{~m}$, isto é, igual a $9,70 \mathrm{~m}$, foi concluído que, no estado em que se encontrava o Túnel 2 durante o ensaio, não seria possível a adução dos $33 \mathrm{~m}^{3} / \mathrm{s}$ previstos em projeto.

Como existia entulho distribuído ao longo do túnel e água represada em extensas bacias resultantes de imperfeições da escavação na bancada, isso alterava as condições do escoamento, devido à redução na área das seções do túnel. Isto posto, tornava necessária uma correção levando em conta essa situação.

Realizadas tais correções, concluíram que a perda total seria de 14,84 m, ainda superior à diferença entre as cotas fixas de montante e jusante, isto é, a 9,70 m. Concluiu-se, portanto, que mesmo com a remoção dos entulhos não seria possível o túnel aduzir os $33 \mathrm{~m}^{3} / \mathrm{s}$ previstos.

Para a solução do problema, ou seja, para que o túnel pudesse aduzir a vazão prevista, a equipe responsável pelo ensaio sugeriu o quanto ainda deveria o túnel ter sua bancada rebaixada. Nos cálculos efetuados, chegaram à conclusão de que o comprimento que o túnel tinha de ser escavado, rebaixando-se a bancada a partir de suas duas extremidades, era de $1732 \mathrm{~m}$, com a hipótese de iguais comprimentos a partir de cada extremidade da bancada.

Durante o ensaio, já estavam rebaixados cerca de 2 mil m, restando $2.826 \mathrm{~m}$ para serem rebaixados. O ensaio evitou o rebaixamento de $1.094 \mathrm{~m}$, o que representou tanto economia financeira quanto de tempo para as obras do Túnel.

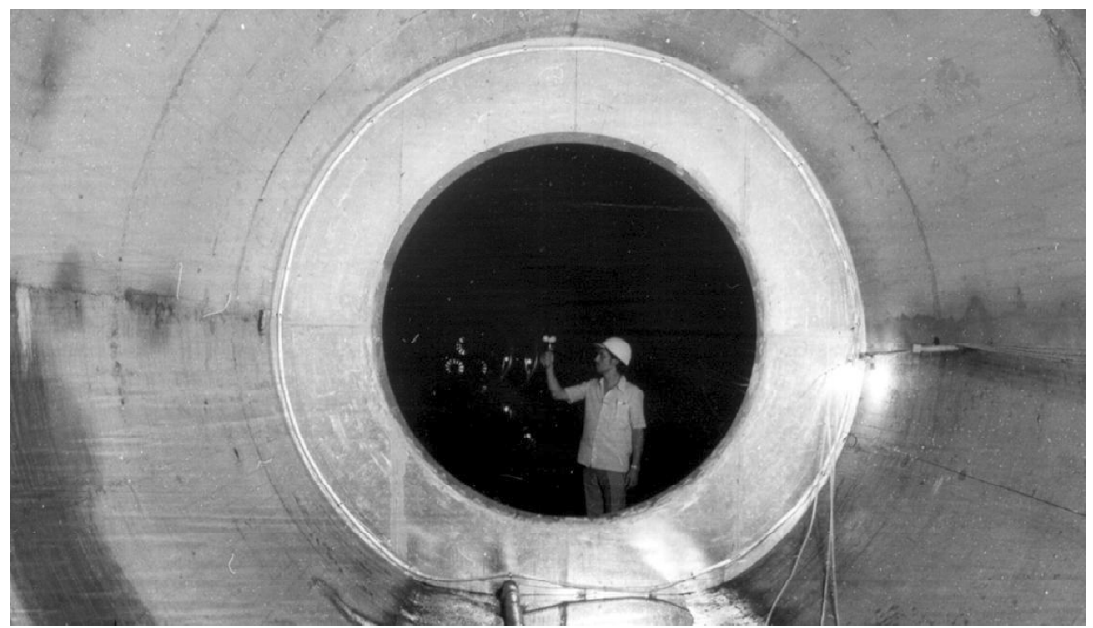

Figura 4.Diafragma usado para medir a vazão de ar.

Após a execução do ensaio preliminar do Túnel 2, o SHS foi novamente solicitado, em 1972, para a realização do ensaio definitivo, nos mesmos moldes do ensaio anterior. 
Houve poucas diferenças entre os dois ensaios. Com um tempo maior entre a contratação do ensaio e a sua realização, foi possível planejar com mais detalhes cada etapa, como por exemplo, o ensaio dos ventiladores usados em campo. Contando como túnel já finalizado, neste ensaio se optou pela instalação do diafragma no trecho revestido de jusante.

A partir da combinação de 2,2 e $1 / 2$ e 3 ventiladores, foram obtidas as vazões utilizadas no segundo ensaio: estas variaram de $33,11 \mathrm{~m}^{3} / \mathrm{s}$ a $46,53 \mathrm{~m}^{3} / \mathrm{s}$. As medidas de vazão efetuadas durante o ensaio foram corrigidas mediante a utilização do coeficiente de vazão obtido com o ensaio do modelo reduzido realizado no laboratório do SHS.

Para traçar a curva mais provável das perdas, foi feita uma programação para computador, que, por meio do método dos mínimos quadradas, interpolou uma parábola através das nuvens de pontos correspondentes ao ensaio nas três situações (2, 2 e $1 / 2$ e 3 ventiladores).

A curva das perdas foi obtida com o plotter do computador IBM 1130, do Centro de processamento de dados da EESC. Também como auxilio do computador, foi obtido o valor da constante que relaciona a perda de carga com a vazão. Assim, foi calculado o valor previsto para a perda quando escoasse através do túnel a vazão de $33 \mathrm{~m}^{3} / \mathrm{s}$. O valor obtido foi de 7,42 m.

A perda total quando da vazão de $33 \mathrm{~m}^{3} / \mathrm{s}$ de água tem de se igualar à diferença de cotas entre montante $(857,10 \mathrm{~m})$ e jusante $(847,40 \mathrm{~m})$, ou seja, 9,70 m. Como o valor obtido pelo segundo ensaio foi inferior ao valor máximo, concluiu-se que, nas condições em que se encontrava o túnel por ocasião do ensaio de perda de carga, a vazão que o Túnel 2 poderia aduzir era de até $37,7 \mathrm{~m}^{3} / \mathrm{s}$.

\section{O Método Óptico}

No caso do Túnel 2, a determinação das seções com a maior precisão possível se fez necessária devido ao fato da rugosidade relativa, $\varepsilon / \mathrm{DH}$, e do diâmetro hidráulico, DH, serem fundamentais para o cálculo da perda de carga e, consequentemente, na determinação do rebaixamento ideal para que esse pudesse escoar a vazão de $33 \mathrm{~m}^{3} / \mathrm{s}$ de água.

Frente à necessidade da realização do levantamento das seções do Túnel 2, a equipe responsável pela previsão da perda de carga desenvolveu um equipamento e um método específicos para determinar a área e do perímetro das seções ao longo do Túnel 2, que foi denominado Método Óptico. Esse método consiste da fotografia de uma seção da galeria convenientemente iluminada por um projetor constituído de uma fonte luminosa, colocada entre dois discos concêntricos opacos, afastados entre si por uma pequena distância, que quando colocado no interior do túnel, gerava um 
plano luminoso e bem determinado nas paredes da galeria. A partir da fotografia desse plano eram determinadas as características geométricas da seção. AFigura 5 ilustra o perfil obtido através do Método Óptico.

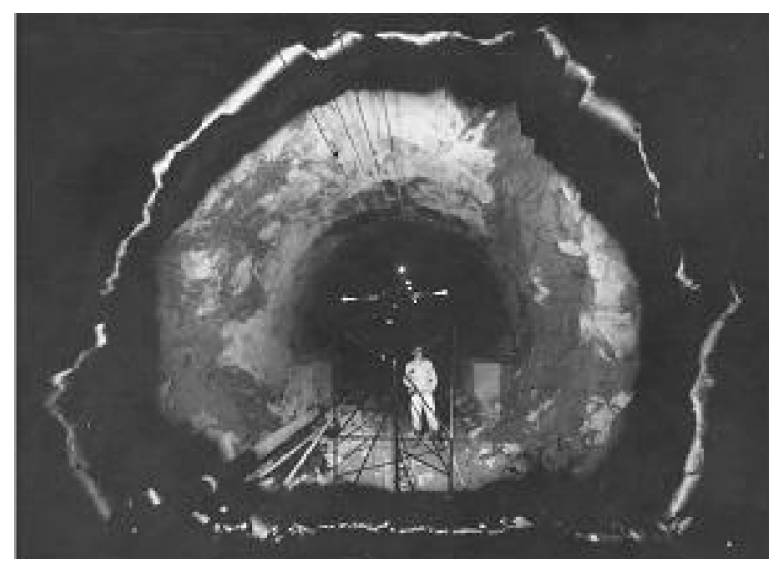

Figura 5. Exemplo de um perfil do Túnel 2 obtido com o Método Óptico.

\section{CONSIDERAÇões FINAIS}

Antes do ensaio preliminar, foram publicadas no Congresso Brasileiro de Engenharia Sanitária no Recife, de 27 de julho a 2 de agosto de 1969, algumas das técnicas que seriam utilizadas para a avaliação da capacidade de escoamento do túnel. Entre essas publicações estão a descrição do Método Óptico - Diâmetro Hidráulico de Seções Irregulares: Determinação por Método Óptico (Aren,1969) -, a calibração do diafragma medidor de vazão - Determinação da Vazão de Água em Túnel por Circulação de Ar. Dimensionamento de Diafragma e seu Modelo Reduzido - Contin Neto et al., 1969) - e uma descrição geral do método a ser utilizado na obtenção das perdas de carga - Determinação da Perda de Carga Hidráulica por circulação de Ar (Sanches et al., 1969). Neste último, os autores concluem que: "... o ensaio de uma canalização de água por circulação de ar é de execução relativamente simples, sendo seus resultados de grande valia no dimensionamento seguro e na construção econômica de grandes túneis de adução de água" (Sanches et al., 1969).

Essa afirmação, sem dúvida, está baseada nos resultados obtidos por Remeniéras e Bourguignon, publicados no ano de 1953 na revista francesa Le Génie Civil, pois ainda não havia sido realizado no Brasil nenhum outro trabalho com o uso dessa metodologia.

Os professores da EESC que participaram da elaboração e execução dos ensaios realizados no Túnel 2 do Sistema Cantareira, e foram entrevistados para este trabalho, 
têm uma posição unânime quando afirmam que, na época da realização dos ensaios no Brasil e até mesmo hoje, não existia outro método para determinar a vazão do túnel senão por meio da circulação de ar. Os professores entrevistados para a realização do trabalho aqui apresentado concordam com outra questão, a de que a assessoria prestada à Comasp, entre os anos de 1969 e 1972, teve um papel fundamental na formação do Departamento de Hidráulica e Sanemento (SHS) da Escola de Engenharia de São Carlos (EESC); essa assessoria foi responsável, no início do ano de 1969, pela formação de um grupo com profissionais da Hidráulica e da Mecânica dos Fluidos, mesmo antes de essas áreas terem se juntado em um único departamento com a reforma universitária. O objetivo primeiro do grupo era a realização dos ensaios, mas esse não era o principal; segundo o Prof. Ruy Vieira, formador do grupo e responsável pelos trabalhos deste, o objetivo principal era a formação de um "departamento forte".

Os ensaios são descritos, na maioria dos depoimentos, como um desafio, tanto pela falta de estrutura física como tecnológica (na época em que os ensaios foram realizados, os computadores estavam em início de expansão tecnológica e de disponibilidade, e havia falta de recursos financeiros).

Como pode ser constatado nas correspondências relativas aos ensaios, grande parte dos equipamentos foram adquiridos por empréstimos de outras escolas, adquiridos pela Comasp, ou ainda construídos pela equipe responsável pelos ensaios. Um exemplo de que a estrutura física também era responsável por tornar os ensaios um desafio - logo após o primeiro ensaio, com recursos provenientes deste, foi construído o edifício Euclides da Cunha, para abrigar a secretaria e os professores do SHS.

Além das dificuldades citadas acima, alguns problemas ocorridos durante os ensaios causaram uma certa "insegurança" na equipe. Um desses problemas era o tempo de resposta nos equipamentos medidores de pressão para a medida da perda de carga no escoamento de ar, em milímetros de coluna de água entre os extremos do túnel; para tanto, foram utilizados dois manômetros tipo Betz, inseridos nos extremos do túnel. Com essa instalação, foi possível obter duas leituras da mesma diferença de pressão, para maior garantia na precisão dos resultados, como mostram os relatórios relativos aos ensaios.

A medida da vazão do ar por meio do diafragma foi obtida, também, com dois manômetros tipo Betz, ambos inseridos na tubulação, e cujas tomadas extremas foram colocadas a montante e a jusante do diafragma. Essa medida sofreu uma correção em razão da diferença entre as massas específícas do ar à pressão atmosférica padrão (para a qual a curva de calibração do diafragma foi feita) e a massa específica do ar a montante do diafragma. Como para a estabilização das 
leituras eram necessários em média 90 minutos, devido ao comprimento da tubulação utilizada para ligação do manômetro óptico às extremidades do túnel, foram considerados apenas os pontos anotados depois de 90 minutos.

Muitos diferentes métodos e instrumentos têm sido usados para construção de túneis, tanto no Brasil quanto em outros países; isso limita esta pesquisa a apresentar outros ensaios semelhantes a esses realizados no Túnel 2 do Sistema Cantareira e na hidroelétrica de Pont-Escofier. São dois os fatores limitantes. O primeiro é que muitas empresas responsáveis por obras desse tipo desenvolvem suas próprias técnicas, mas não têm publicado seus detalhes. Segundo, com o advento da computação e a grande diversidade de equipamentos que realizam as medições feitas nos ensaios, não é possível, neste trabalho, fazer uma completa análise de cada sistema possível de ser utilizado para realizar um ensaio com circulação de ar nos dias de hoje.

O Método Óptico, por exemplo, desenvolvido para a medição do diâmetro hidráulico do túnele determinação da rugosidade relativa, proporcionou agilidade e versatilidade no levantamento das características do túnel. Até o ano de 1969, nenhum outro método, com tais características, era conhecido por seus idealizadores.

Hoje, porém, tornou-se obsoleto com a utilização do laser nos equipamentos topográcos atuais, como a estação total. Os quilômetros de mangueiras usados nos ensaios do Túnel 2 podem ser substituídos por sensores eletrônicos, cuja maior parte das conexões e transmissão de dados podem ser feitas não mais com fios, mas por ondas de rádio (Pinheiro, 2006).

\section{REFERÊNCIAS}

AZEVEDO NETTO, J. JUNIOR, E. F. B.; MACEDO, L.H. H. Estação de Tratamento de Água do Guaraú: Solução metropolitana dentro da realidade brasileira, Revista DAAE. V. 110, P. 28-40, 1978.

PINHEIRO, H. D. Perspectiva Histórica e Tecnológica da Calibração do Túnel 2 do Sistema Cantareira de Adução de Água para a Região Metropolitana de São Paulo. São Carlos: Escola de Engenharia de São Carlos - Universidade de São Paulo, 2007.

REMENIÈRAS G.; BOURGUIGNON, P. "Prédétermination des pertes de charge d'une canalisation d'eau par circulation d'air". Le Génie Civil., v.130, n.6, p. 108-111, 1953a.

SHS. Ensaio de Perda de Carga do Túnel 2 - Sistema Cantareira. São Carlos: 
Departamento de Hidráulica e Saneamento da Escola de Engenharia de São Carlos, Universidade de São Paulo, 1972.

AREN, H. G. Diâmetro hidráulico de seções irregulares: Determinação por Método Óptico. Revista DAAE, v.72, p.287-293, 1969.

CONTIM NETO, D. "Determinação da vazão de Água em túnel por circulação de ar. Dimensionamento de diafragma e seu modelo reduzido. Revista DAAE, v.72, p. 295-299, 1969.

SABESP. O sistema Cantareira, 2006. Disponível em: http:// www.sabesp.com.br, Acesso em: 25.jan. 2009.

SANCHES, M. G.; VERAS, M. C.; MATTOS, S. O "Determinação da perda de carga hidráulica por circulação de ar. Revista DAAE, v. 72, p. 281-286, 1969.

Title: Tests for Tunnel 2 of the Cantareira Water Project for the Metropolitan Area of São Paulo- a Historical and TeChnological RevieW

\section{ABSTRACT}

This article relates a work that was carried out between the end of the 1960's and the beginning of the 1970's, by the Chair of Fluid Mechanics (precursor of the Departamento de Hidráulica e Saneamento of the Escola de Engenharia de São Carlos - Universidade de São Paulo), with the objective of foreseeing the water flow rate at Tunnel 2 of the Cantareira Water Project for the Metropolitan Area of São Paulo. An original test using air circulation was carried out in the tunnel. Methods and techniques were developed in order to verify the flow rate and check its size, to guarantee $33 \mathrm{~m}^{3} / \mathrm{s}$ of flow. The documents produced by the authors of the test were surveyed, organized chronologically and analyzed, seeking to infer the theoretical influences that had guided the methodologies, to describe the techniques and technologies and to analyze, in accordance with the document registers, the execution and the results reached by the tests.

KEYWORDS: Tests of the tunnel for water flow rate; Sistema Cantareira, Historical review. 